\title{
BUDAYA INTERNET: PERKEMBANGAN TEKNOLOGI INFORMASI DAN KOMUNIKASI DALAM MENDUKUNG PENGGUNAAN MEDIA DI MASYARAKAT
}

\author{
Jokhanan Kristiyono \\ STIKOSA-AWS Surabaya \\ Jl. Nginden Intan Timur I/18, Surabaya, INDONESIA \\ e-mail: yokhanan@gmail.com
}

\begin{abstract}
ABSTRAK
Munculnya Internet sebagai media komunikasi baru telah dikaitkan dengan klaim yang bertentangan tentang munculnya pola baru interaksi sosial. Ide komunitas virtual maju sebagai pelopor interaksi sosial pada Internet. Penggunaan internet yang begitu tinggi, akhirnya dapat menimbulkan permasalahan sosial baru yang cukup besar contohnya timbul masalah komunikasi yang berlebihan menggunakan elektronika kepada personal hingga dapat mengurangi bentuk-bentuk interaksi hubungan komunikasi antar personal, bahkan sangat lazim kita temui informasi pribadi kepada seseorang dipublikasikan secara umum menggunakan status media sosial yang akhirnya membuat ruang publik seoalah merupakan ruang pribadi. Media literasi atau tingkat pengetahuan dalam penggunaan media menjadi hal yang sangat penting untuk dapat menggunakan media baru secara baik dan bijak. Dari hasil analisis dan riset studi pustaka maka dapat disimpulkan bahwa pertama, penggunaan media yang berbasis Internet secara berlebihan akan menimbulkan banyak permasalahan mulai dari ketergantungan, perubahan perilaku hingga kejahatan-kejahatan dunia cyber. Kedua, Budaya Internet yang berkembang saat ini tercipta karena ada sinergi dari 4 budaya di dalamnya yaitu, budaya Teknokratis, budaya Hacker, Budaya Virtual Communitarians dan terakhir budaya Entrepreneurial. Ketiga, Media Education atau pendidikan dalam menggunakan Media menjadi hal yang sangat penting untuk menumbuhkembangkan literasi media.
\end{abstract}

Kata kunci: Internet, interaksi sosial, media literasi, dunia cyber, budaya internet.

\begin{abstract}
The emergence of The Internet as a new communication medium has been associated with conflicting claims about the rise of new pattern of social interaction. The idea of virtual communities advanced by the pioneers of social interaction on the Internet. High Internet usage can eventually lead to new social problems, the example problem is excessive use of electronic communication to personal that is reducing the forms of interaction between personal communication, even very unusual we find out personal information to someone published in general use social media status even tough that is very personal problems. Conclusion from the research are: First, the use of Internet-based media in excess will cause a lot of problems ranging from addiction, behavioral changes to crimes cyber world. Second, the Internet culture developed at this time because there is a synergy created from four cultures in it, namely, Technocratic, Hacker, Virtual Communitarians, and Entrepreneurial. Third, Media Education or training in using the media becomes very important to foster media literacy..
\end{abstract}

Keywords: Internet, social interaction, media literacy, cyber world, internet culture.

\section{PENDAHULUAN}

Perkembangan komunikasi dewasa ini tidak akan terlepas dengan adanya perkembangan teknologi informasi dan komunikasi itu sendiri, semakin tinggi teknologi informasi dan komunikasi yang ditemukan dan digunakan maka itu tidak terlepas dari bagaimana perkembangan komunikasi di masyarakat dan bagaimana masyarakat sosial tersebut berinteraksi. Secara khusus masyarakat sosial di perkotaan atau di kota-kota besar, jalinan interaksi komunikasi terbangun dengan berdasarkan perkembangan teknologi terutama teknologi informasi dan komunikasi. Sangat lazim ditemui oleh kita semua di dalam masyarakat sosial kota tiap individu atau orang pasti mempunyai satu atau lebih alat komunikasi yang tercipta dengan adanya perkembangan teknologi, salah satu contohnya adalah smartphone baik yang berbasis operating system android, windows mobile hingga iOS semuanya terhubung atau terkoneksi dengan internet.

Masyarakat sosial di kota besar khususnya, hampir selalu menggunakan internet dalam melakukan interaksi komunikasi mulai dari komunikasi pribadi atau personal hingga komunikasi secara formal semuanya selalu didukung dengan adanya jaringan internet. "Communication always on your hand", interaksi komunikasi sekarang selalu dalam geng- 
gaman dengan menggunakan smartphone atau alat komunikasi pintar ini orang selalu terkoneksi dengan internet hingga dapat selalu berkomunikasi dengan siapapun, dimana pun dan kapan pun. Masyarakat menjadi sangat tergantung dengan adanya piranti komunikasi pintar ini (baca: smartphone), hingga merekapun rela ketinggalan dompet daripada ketinggalan smartphone-nya karena menurut mereka jika tidak dapat menggunakan alat tersebut maka dunia seperti gelap tidak terhubung dengan dunia luar (internet). Masyarakat yang selalu terkoneksi dengan internet atau bisa disebut "Always On" ini tidak hanya untuk kalangan dewasa saja atau orang-orang yang mempunyai pendidikan dan ekonomi yang cukup, bahkan anak-anak hingga remaja menunjukkan angka yang cukup tinggi dalam penggunakan smartphone dan selalu terkoneksi dengan internet. Internet merupakan medium komunikasi, komunikasi yang terjadi pada skala global dan pada saat ini kita memasuki komunikasi dunia baru: the Internet Galaxy. ${ }^{1}$

Menurut data hasil penelitian Asosiasi Penyelenggara Jasa Internet Indonesia (APJII) dan Pusat Kajian Komunikasi (Puskakom) bahwa penggunaan internet Indonesia tahun 2014, sebanyak 88,1 juta. Angka pengguna sebesar 88,1 juta tersebut disesuaikan dengan jumlah penduduk Indonesia menurut data Badan Pusat Statistik (BPS) tahun 2014 sebesar 252 juta penduduk. dengan demikian dari sisi jumlah penduduk bahwa pengguna internet mengalami pertumbuhan 16,2 juta pengguna, yaitu dari 71,9 juta menjadi 88,1 juta pengguna. Dalam penelitian ini APJII dan Puskakom tersebut tidak hanya melibatkan pengguna dan data isian kuesioner Internet Service Provider (ISP) anggota APJII. Survey yang dilakukan terhadap 2000 pengguna internet di 42 kota baik urban dan rural Indonesia sekaligus memberikan gambaran demografis pengguna internet, perilaku serta gaya hidup mereka yang secara keseluruhan menggambarkan tren penggunaan internet di Indonesia $^{2}$.

Dari hasil penelitian tersebut, yang menarik adalah usia pengguna Internet di Indonesia 18-25 tahun sebesar 49\%, hampir setengah dari jumlah keseluruhan penggunaan internet di Indonesia. Ini menunjukkan bahwa pada usia 18-25 tahun tersebut masuk kategori Digital Native atau penduduk/manusia yang

\footnotetext{
${ }^{1}$ Castells, the Internet Galaxy: Reflection on the Internet, Business and Society

${ }^{2} \mathrm{http} / / /$ www.apjii.or.id/v2/read/content/info-terkini/301/penggunainternet-indonesia-tahun-2014-sebanyak-88.html, diakses terakhir 13 Mei 2015
}

lahir dan bertumbuh kembang pada masa teknologi sudah berkembang pesat khususnya teknologi digital dengan kelompok usia yang lahir pada tahun 1990an hingga 2000an. Pada tahun 1990 hingga 2000 merupakan masa berkembang pesatnya dunia internet dan mulai dikenal secara luas oleh masyarakat hingga mulai munculnya dunia jejaring sosial seperti Myspace, Friendster hingga Facebook.

Tabel 1. Penggunaan Internet

\begin{tabular}{lc}
\hline \multicolumn{1}{c}{ Aktifitas Internet } & Prosentase \\
\hline Aplikasi/Konten Media Sosial & $87,4 \%$ \\
Searching & $68,7 \%$ \\
Messaging & $59,9 \%$ \\
Berita & $59,7 \%$ \\
Download/Upload Video & $27,3 \%$ \\
\hline
\end{tabular}

Sumber: olahan data penelitian APJII

Penggunaan internet yang begitu tinggi, akhirnya dapat menimbulkan permasalahan sosial baru yang cukup besar contohnya timbul masalah komunikasi yang berlebihan menggunakan elektronika kepada personal hingga dapat mengurangi bentuk-bentuk interaksi hubungan komunikasi antar personal, bahkan sangat lazim kita temui informasi pribadi kepada seseorang dipublikasikan secara umum menggunakan status media sosial seperti blackberry messenger, facebook, twitter, dan lain sebagainya. Permasalahan kedua yaitu pengguna internet menghabiskan waktunya terlalu lama dengan media elektronik hingga sampai lupa waktu dan lupa segalanya, banyak permasalahan timbul karena penggunaan media elektronika internet yang terlalu berlebihan, terutama permasalahan kesehatan. Permasalahan ketiga yang tidak kalah hebatnya adalah munculnya permasalahan social isolation and neurosis ${ }^{3}$, karena perilaku yang salah pada penggunaan mobile phone (smartphone), internet devices, game online. Banyak sekali permasalahan social isolation dan neurosis ini muncul pada kalangan anak muda atau remaja karena perilaku penggunaan internet yang berlebihan seperti memainkan game online yang melebihi batas kewajaran hingga menyebabkan perubahan perilaku pada remaja tersebut seperti sikap yang kasar dan agresif, selain itu permasalahan Intimidasi di dunia cyber atau biasa disebut cyber bullying ("Cyberbullying" adalah ketika seorang anak, praremaja atau remaja yang disiksa,

\footnotetext{
${ }^{3}$ Permasalahan sosial dikarenakan hampir tidak ada kontak dengan orang lain atau masyarakat, yang merupakan sebuah zona diri individu dari masyarakat dan hampir tidak memiliki interaksi dengan manusia atau orang lain. Neurosis adalah gangguan fungsional di mana kepribadian individu didominasi (tingkat yang sangat tinggi) sebagai berikut: 1. Kecemasan. 2. tindakan kompulsif. 3. pikiran obsesif. 4. keluhan fisik tanpa bukti objektif penyakit.
} 
diancam, dilecehkan, dihina, malu atau ditargetkan oleh anak lain, praremaja atau remaja menggunakan internet, teknologi interaktif dan digital atau ponsel) di kalangan anak muda atau remaja khususnya para siswa sekolah saat ini juga kerap terjadi seperti kejadian bunuh diri siswa sekolah di salah satu kota di Amerika Serikat karena anak ini tidak tahan perlakuan kasar yang dilakukan teman-teman sekolah pada dirinya yang tidak hanya terjadi di sekolah tetapi terus mengganggu dirinya hingga pada ruang-ruang pribadi di dunia Internet seperti facebook, myspace dan lainnya.

Penelitian terdahulu dengan judul Literasi Internet pada Siswa Sekolah Menengah Pertama oleh Noneng Sumiaty dan Neti Sumiaty pada Jurnal Penelitian Komunikasi Vol 17, No. 12014 (http://jurnal. kominfo.go.id, diakes terakhir 16 Juli 2015) mengenai Literasi internet yang sangat diperlukan untuk mengetahui perkembangan dunia dalam berbagai hal secara cepat dan tepat, begitu juga dalam dunia pendidikan. Fokus penelitian ini adalah: Bagaimana tingkat literasi internet pada siswa SMPN 8 Kabupaten Purwakarta? Tujuan penelitian ini untuk mendapatkan informasi tentang tingkat literasi internet pada siswa SMPN 8 Kabupaten Purwakarta. Metode yang digunakan dalam penelitian ini adalah deskriptif kualitatif. Populasi penelitian adalah seluruh siswa kelas 8, sedangkan sampel diambil dari tiap kelas dua siswa; sementara siswa kelas 8 ada 7 kelas. Jadi, keseluruhan sampel berjumlah 14 informan. Teorinya diadopsi dari Ciolek, Matthew (2003) tentang pemahaman dan penguasaan internet yang terdiri dari: basic skill, moderate skill, dan advanced skill. Hasil penelitian menunjukkan bahwa hanya sedikit informan yang telah menguasai dan memahami secara keseluruhan tingkat tentang penguasaan internet. Sebagian besar siswa SMPN 8 hanya menguasai dan memahami tingkat dasar saja. Diharapkan siswa SMPN 8 mengusai dan memahami seluruh tingkatan pemahaman internet secara bertahap.

\section{TINJAUAN PUSTAKA}

\subsection{Global Village Marshall McLuhan hingga perubahan budaya Cyberculture}

Kultur yang tercipta dan berkembang di dunia elektronika atau digital sudah sejak lama diprediksi oleh seorang pakar media yaitu Marshal McLuhan yang bisa melihat secara detil dan jelas bagaimana kultur media elektronik akan memberikan pengaruh yang sangat besar hingga dapat merubah kehidupan sosial di masyarakat dalam penggunaan media khususnya media elektronik. Tahun 1960, McLuhan melihat gambar mozaik yang dimunculkan teknologi baru pada saat itu sebagai antithesis terhadap zaman tipografik, media cetak menjauhkan manusia dari dunia dan sesamanya sementara media elektronik membuat manusia lebih tergantung dan dapat menciptakan kembali dalam gambaran sebuah perkampungan global atau global village. ${ }^{4}$

Perkembangan media elektronik dan digital juga sangat mempengaruhi perubahaan kehidupan manusia, terutama digunakannya Internet dalam medium komunikasi. Internet yang pada awalnya diciptakan sebagai jaringan eksperimental oleh riset militer Amerika Serikat (AS) untuk mendukung negara tersebut dalam perang dingin tahun 1969 akhirnya mengalami perkembangan yang sangat cepat, sepanjang tahun 1980an Internet tersebar ke lembagalembaga pendidikan atau akademik dan pusat-pusat riset di AS hingga ke banyak lokasi lain di seluruh dunia. Mendekati tahun 1995, sudah 30 juta orang dari 100 negara telah menggunakan Internet dengan memperoleh akses melalui computer kepada layanan berita, bulletin board, database serta komunikasi interpersonal.

Evolusi komunikasi umat manusia memberikan dukungan besar pada perubahan media atau bisa kita sebut mediamorfosis, dalam periode yang cukup singkat perubahan media atau mediamorfosis terjadi karena perubahan teknologi yang tercipta oleh agenagen perubahan yang memiliki pengaruh besar terhadap semua individu, waktu dan realitas itu sendiri dengan adanya media baru (new media) yang muncul dan tersebar ke seluruh dunia. ${ }^{5}$ Perubahan pola komunikasi dari yang tatap muka atau face-toface menjadi termediasi dan dikontrol oleh media baru di dunia Internet, perubahan pola komunikasi ini juga membuat perubahan besar dalam pola penggunaan media khususnya media baru yang akhirnya terciptalah sebuah budaya cyber (cyberculture) dalam lingkungan cyber (cyber space).

\subsection{Budaya pada Internet}

Perkembangan teknologi muncul karena diproduksi dan berkembang dengan adanya budaya dan sosial pada masyarakat, termasuk tanpa kecuali perkembangan internet di masyarakat. Budaya pada internet

\footnotetext{
${ }^{4}$ Fidler, Mediamorphosis, 146

${ }^{5}$ Rogers, Diffusion of Innovation
} 
mempunyai empat struktur lapisan yaitu: budaya tekno-meritocratic atau biasa disebut Teknokratis, budaya Hacker, budaya komunitas virtual dan budaya entrepreneurial. Secara bersama-sama, keempat struktur lapisan budaya tersebut memberikan kontribusi yang besar pada kebebasan ideologi Internet di dunia. $^{6}$

Budaya Teknokratis muncul pertama kali pada orangorang yang berkecimpung di dunia akademik dan sains, budaya Teknokratis ini percaya bahwa teknologi yang dihasilkan oleh bidang keilmuan atau sains merupakan komponen penting dalam perkembangan umat manusia di dunia. Teknologi-teknologi baru khususnya di dunia internet semua diciptakan dan dibuat untuk kebaikan hingga perkembangan kebutuhan umat manusia. Teknologi itu diciptakan untuk semua orang dan seharusnya semua orang bisa mengakses atau menggunakannya secara gratis tanpa pengecualian, itu merupakan pola pikir dasar atau mindset dari budaya kedua yaitu budaya Hacker. Hacker bukan seperti yang media massa atau masyarakat tahu pada saat ini, mereka bukan orangorang yang menjebol kode-kode rahasia dari computer untuk kepentingan diri sendiri dan merusaknya, atau bahkan masuk ke sistem perbankan secara online di Internet dan mencuri data-data rahasia hingga memindah data keuangan untuk kekayaan diri sendiri atau orang lain. Semua yang dilakukan yang tujuannya untuk merusak sistem teknologi itu disebut Cracker, sebuah perilaku yang salah bahkan bisa dibilang tindakan kejahatan di dunia cyber atau biasa disebut cyber crime ini merupakan karakteristik etika yang berbanding terbalik dengan Hacker. ${ }^{7}$

Komunitas virtual atau biasa disebut Virtual Communitarians, mempunyai andil yang sangat besar pada perkembangan teknologi khususnya di dunia Internet. Teknologi hingga aplikasi baru di dunia internet yang diciptakan para innovator seperti browser, website, social media, dan lain sebagainya muncul dan tercipta berdasarkan pola perilaku penggunaan media di internet. Komunitas di dunia maya atau Virtual Community semakin lama semakin bertumbuhkembang dalam jumlah dan jangkauan, nilai dan keinginan yang muncul pada komunitas ini membuat pertumbuhan dan perkembangan teknologi komunikasi di dunia internet semakin tinggi. Perilaku penggunaan internet untuk berinteraksi dan berkomunikasi secara personal dan grup menimbulkan kebutuhan-ke-

\footnotetext{
${ }^{6}$ Castell, Internet Galaxy, 37

${ }^{7}$ Peka, The Hacker Ethic and the Spirit of the Information Age
}

butuhan yang baru hingga membuat pencipta teknologi merancang dan menciptakan aplikasi baru untuk memenuhi kebutuhan komunitas itu, contoh adalah aplikasi google circle yang tercipta karena adanya perilaku komunikasi email pemilik akun google yang berinteraksi secara itens dengan teman atau orang lain yang memiliki akun di google juga. Google circle menciptakan lingkaran komunitas baru berdasarkan itensitas komunikasi dan iteraksi kita menggunakan email google.

Pada kultur entrepreneurial, tidak dapat dipungkiri bahwa Bill Gates dengan gurita perusahaan teknologi Microsoft sangat mempengaruhi perkembangan teknologi di dunia. Hampir semua instansi dan perusahaan di dunia ini pasti didukung software Microsoft pada semua computer yang digunakan di perusahaan tersebut, mulai dari operating system hingga aplikasi software office. Contoh lain adalah Steve Jobs, seorang innovator bidang teknologi yang tidak lulus sarjana tetapi sejak muda hidup dalam kultur teknokratis dengan menciptakan teknologi baru lalu bergeser dan berkembang mengalami budaya entrepreneurial teknologi hingga dapat membidani lahirnya perusahan teknologi Apple yang saat perusahaan ini menjadi raksasa di dunia teknologi. Dapat disimpulkan bahwa keempat bentuk budaya mulai dari Teknokratis, Hackers, Virtual Communitarians hingga budaya entrepreneurial saling terkait dalam pengembangan teknologi komunikasi di dunia Internet.

\subsection{Media Literasi dalam penggunaan Media Baru}

Media literasi atau tingkat pengetahuan dalam penggunaan media menjadi hal yang sangat penting untuk dapat menggunakan media baru secara baik dan bijak. Penggunaan media baru (new media) di Intenet yang dilakukan oleh masyarakat merupakan bentuk partisipasi dan keaktifan dalam kehidupan sosial dan bermasyarakat, lingkungan masyarakat dalam kehidupan sosial mempunyai nilai-nilai budaya dan sosial seperti norma atau bisa kita sebut deontological values mempunyai pribadi yang menggunakan media tersebut seharusnya patuh dan secara sadar mengetahui norma-norma yang terkontruksi sejak lama dalam kehidupan sosialnya. Kebebasan memperoleh informasi (right to information) dan kebebasan orang dalam memberikan informasi dalam kehidupan demokrasi masyarakat menjadi hal utama dalam penggunaan media, dan bagaimana bentuk-bentuk partisipasi dalam ruang publik hingga kebebasan berekpresi yang akhirnya membuat orang menjadi 
konsumtif dan berlebihan dalam penggunaan media khususnya media-media baru di Internet seperti facebook, twitter dan sosial media lainnya. Kita tahu banyak sekali pelanggaran-pelanggaran yang terjadi hingga kejahatan-kejahatan baru yang muncul karena penyalahgunaan media baru tersebut, seperti twitter menjadi media prostitusi online. Semakin sempitnya ruang publik yang nyata di masyarakat untuk dunia prostitusi dengan gencarnya pemerintahan menutup daerah-daerah prostitusi tersebut membuat terciptanya ruang-ruang publik baru di cyberspace atau dunia cyber yang menimbulkan kejahatan di dunia cyber atau bisa kita sebut cybercrime.
Pembentukan kemampuan penggunaan media (media literasi) yang baik itu tercipta karena adanya literasi membaca dan menulis (reading and writing literate), literasi audio visual dan digital literacy. Semua itu dapat membentuk seseorang menjadi kritis dalam penggunaan media baru dan meningkatkan kemampuan hingga kreatifitas dalam penggunaan media tersebut. Kemampuan seseorang dalam penggunaan media diawali dengan adanya pendidikan media, pendidikan secara formal dan pendidikan informal. Khusus pendidikan informal ini yang memiliki kontribusi yang sangat besar dalam memberikan pendidikan media untuk seseorang karena melalui pendidikan

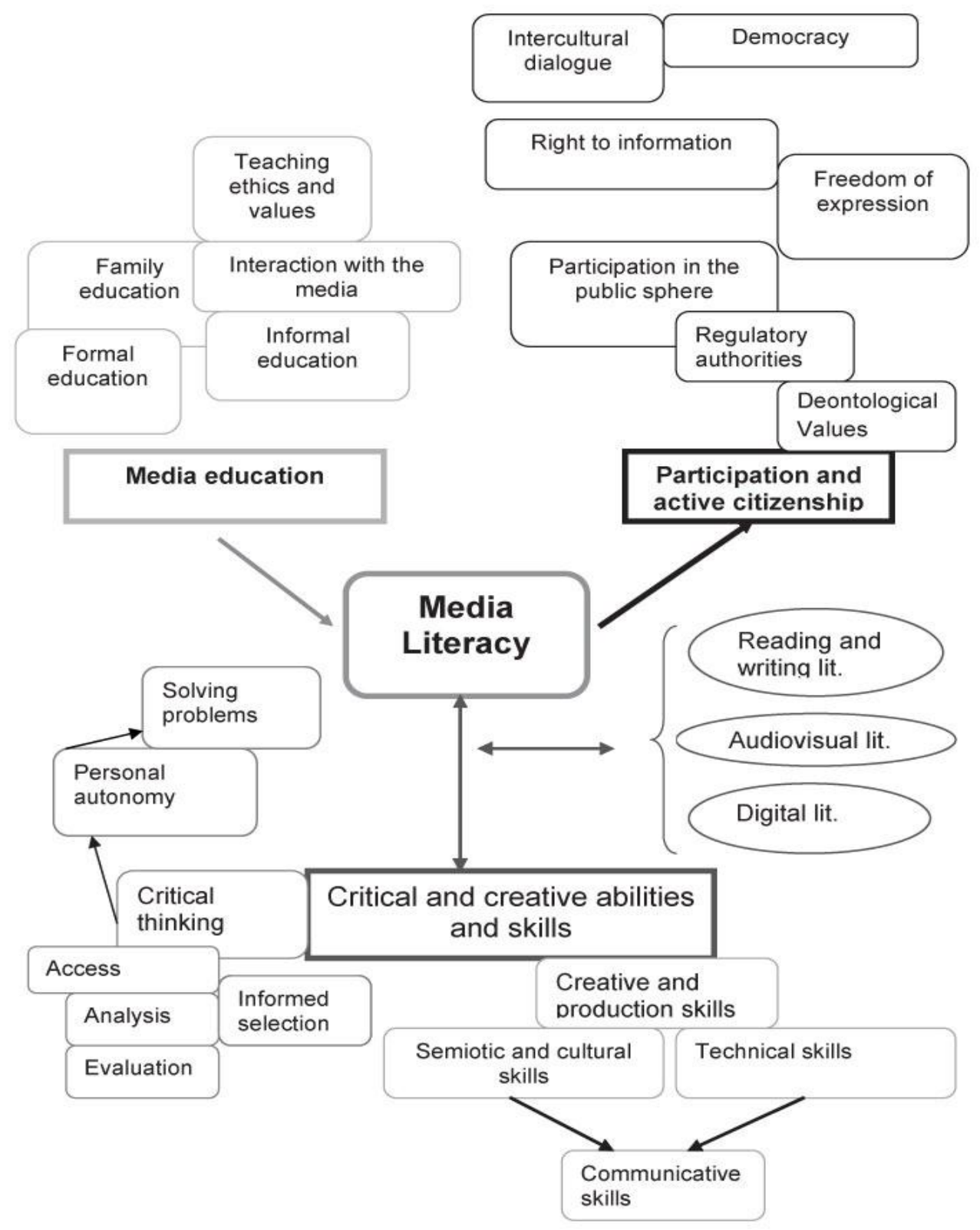

Gambar 1. Bagan Proses Media Literasi

Sumber: Carlsson (2008), Empowerment Through Media Education: an Intercultural Dialogue, hal 106. 
yang dilakukan dalam kehidupan keluarga, bagaimana etika dan nilai-nilai itu diberikan secara informal hingga memberikan pengetahuan dalam interaksi komunikasi menggunakan media secara bijak dan baik itu merupakan cara yang terbaik, optimal dan lebih personal kepada tiap individu atau pribadi untuk membentuk media literasi yang baik. Berikut adalah bagan proses media literasi (Gambar 1).

\section{METODE PENELITIAN}

Metode penulisan artikel ilmiah ini menggunakan metode kualitatif deskritif melalui studi kepustakaan, yaitu riset berdasarkan studi pustaka dan analisis perkembangan permasalahan di masyarakat. Permasalahan yang terjadi di masyarakat saat ini khususnya permasalahan di dunia Internet, penggunaan media di dunia Internet yang tidak bijak dan benar dikarenakan literasi media yang kurang hingga perilaku dan tujuan penggunaan media yang tidak benar membuat mediamedia baru seperti media sosial di Internet yang tercipta karena perkembangan teknologi menjadi alat komunikasi untuk hal-hal buruk. Analisis riset yang dilakukan pada permasalahan ini adalah studi pustaka dengan membaca dan menganalisa teori-teori mengenai new media, media literasi dan budaya Internet agar dapat mengambil suatu kesimpulan untuk hasil penelitian.

\section{DISKUSI KONSEPTUAL}

Perkembangan teknologi informasi dan komunikasi pada hakekatnya ditujukan untuk meningkatkan kesejahteraan masyarakat dalam membangun peradaban bangsa atau dunia. Pada kenyataan menunjukkan bahwa teknologi informasi dan komunikasi telah membawa perubahan penting dalam perkembangan peradaban, terutama perekonomian dunia. Dengan semakin pesatnya pertumbuhan dan perkembangan teknologi komunikasi di dunia pada zaman sekarang ini, tentu saja membawa dampak bagi segala aspek kehidupan tidak terkecuali di Indonesia. Dampak perkembangan teknologi komunikasi membawa beberapa dampak positif dan negatif. Tentu saja perkembangan teknologi komunikasi membawa banyak sekali keuntungan untuk dapat digunakan, tetapi juga menimbulkan tidak sedikit kerugian karena dampak negatif yang muncul karena adanya perkembangan teknologi dan komunikasi.

Dampak positif dari berkembangnya teknologi komunikasi yang terjadi di masyarakat sebagai contoh adalah semua orang dapat menjadi sumber informasi sehingga membuat masing-masing dapat saling bertukar informasi dengan cara berkomunikasi. Sebelum berkembangnya teknologi komunikasi, informasi yang disebar haruslah dengan cara tatap muka. Akan tetapi, setelah adanya perkembangan teknologi komunikasi, informasi itu pun menyebar sampai kepada seluruh lapisan masyarakat dengan cepat melalui media khusunya media komunikasi melalui Internet tanpa harus bertemu atau tatap muka. (Kappas Arvid, 2011).

Dampak negatif yang timbul, seperti yang kita tahu dalam beberapa dekade terakhir ini, teknologi komunikasi telah mengalami perkembangan yang luar biasa. Seperti yang tertuang pada Hukum Isaac Newton ke 3 yaitu tentang gerak menyatakan bahwa setiap tindakan memiliki reaksi yang sama dan berlawanan, ini juga terjadi dengan teknologi komunikasi yang membuat hal-hal berjalan lebih baik, lebih cepat, dan lebih murah, selain itu juga datang dengan kelemahan besar, yang mengubah hidup. Salah satu contoh dampak yang timbul dikarenakan penggunaan teknologi komunikasi Internet pada anak-anak, kaum remaja hingga dewasa, yaitu masyarakat yang terlahir dan bertumbuh kembang pada masa teknologi sudah berkembang pesat khususnya teknologi digital yaitu perubahan perilaku sosial dan munculnya penyakit neurosis atau biasa disebut social isolation and neurosis. Permasalahan sosial dikarenakan hampir tidak ada kontak dengan orang lain atau masyarakat, yang merupakan sebuah zona diri individu dari masyarakat dan hampir tidak memiliki interaksi dengan manusia atau orang lain. Neurosis adalah gangguan fungsional di mana kepribadian individu didominasi (tingkat yang sangat tinggi) sebagai berikut: 1. Kecemasan. 2. tindakan kompulsif. 3. pikiran obsesif. 4. keluhan fisik tanpa bukti objektif penyakit.

Kita semua menyadari, bahwa informasi itu penting. Tidak salah jika ada pomeo yang berbunyi, "siapa yang menguasai informasi, dia akan memenangkan petarungan". Dalam konteks persaingan hidup yang semakin berat dan kompleks dewasa ini, informasi mempunyai kedudukan yang lebih penting lagi. Informasi merupakan sumber pengetahuan. Lebih banyak informasi yang kita dapat, akan lebih luas lagi pengetahuan yang kita punya. Tidak salah memang. Namun banyak yang lupa, sejatinya informasi dari media merupakan bahan mentah dari pengetahuan. Untuk menjadi pengetahuan yang baik dan berguna, perlu diolah lagi dengan saksama. Nah, di sinilah pentingnya literasi media.

Literasi media, yang diterjemahkan secara popular dengan istilah "melek media", saat ini merupakan istilah yang lagi hangat-hangatnya diperbincangkan di 
kalangan pekerja dan pemerhati media. Ini erat kaitannya dengan pengolahan informasi, yang merupakan bahan baku pengetahuan, menjadi pengetahuan yang baik dan berguna. Tidak hanya secara individu dan keluarga, pun secara kelompok, mulai dari kelompok kecil semacam komunitas, hingga kelompok besar masyarakat dalam suatu negara. Pasalnya, informasi yang kita terima saat ini, hampir semuanya berasal dari media. Mulai dari media cetak seperti buku, majalah, dan koran; hingga media elektronik seperti radio, televisi, dan internet. Dengan perkembangan teknologi yang demikian cepat, media dapat diakses dengan lebih mudah, sehingga informasi bisa diterima lebih cepat tanpa dibatasi oleh ruang dan waktu.

Literasi media adalah kemampuan untuk menganalisis, membandingkan, menangkap pesan ekstrinsik dan instrinsik, serta mentransformasikan kembali dengan tepat informasi yang didapat dari media tersebut. Kemampuan yang tampaknya tidak dimiliki oleh mayoritas penikmat media kita. Banyak dari kita menelan mentah-mentah informasi yang dipublikasikan melalui media teknologi seperti jejaring sosial di Internet, misalnya. Dengan menganggap bahwa informasi tersebut seratus persen benar, lalu memberi komentar berdasarkan informasi yang belum tentu benar tersebut. Akhirnya informasi tersebut berkembang keluar dari substansi informasi awalnya. Di negara-negara maju, media literasi sudah dimasukkan ke dalam kurikulum sekolah seperti contoh di Negara Inggris dapat dianggap sebagai pionir dalam hal ini, usaha mereka untuk menanggulangi dampak negatif media, membuahkan sebuah cabang pengetahuan yang kini disebut literasi media. Bahkan lebih jauh dari itu, perkembangan literasi media di Inggris, tidak sebatas kampanye, yang hasilnya "bagaikan air di daun keladi". Sejak tahun 1990, parlemen negara David Beckham tersebut telah mengukuhkan masuknya literasi media ke dalam kurikulum resmi pendidikan. Artinya, seluruh jajaran sekolah di Inggris wajib menyelenggarakan pendidikan literasi media. Masyarakat Inggris dituntut secara merata untuk memiliki kemampuan mengolah rentetan informasi. Badan regulasi khusus yang diberi wewenang untuk menyelenggarakan kurikulum ini adalah Ofcom (Office of Communications). Tak lama setelah pendiriannya di tahun 2004, Ofcom pun menerbitkan ketentuan mengenai draf penyelenggaraan literasi media. Langkah yang kemudian diikuti oleh negaranegara maju lainnya seperti Amerika Serikat. PBB sendiri, melalui UNESCO telah menerbitkan kurikulum Media and Information Literacy (MIL). Kurikulum yang baru saja diterbitkan tersebut berupa buku berjudul Media and Information Literacy Curriculum for Teachers. Negara kita memang ketinggalan dalam hal menanggulangi dampak media terhadap anak-anak, tetapi masih dapat kita kejar dan benahi mengenai pentingnya pendidikan dalam penggunaan media untuk dapat menumbuhkembangkan literasi media baik di pendidikan formal maupun informal atau dalam lingkungan keluarga dan masyarakat.

\section{KESIMPULAN}

Dari hasil analisis dan riset studi pustaka maka dapat disimpulkan sebagai berikut:

1. Penggunaan media khususnya media-media yang berbasis Internet yang berlebihan dan tidak menggunakannya secara bijak maka akan menimbulkan banyak permasalahan mulai dari ketergantungan, perubahan perilaku hingga kejahatan-kejahatan dunia cyber.

2. Budaya Internet yang berkembang saat ini tercipta karena ada sinergi dari 4 budaya di dalamnya yaitu, budaya Teknokratis, budaya Hacker, Budaya Virtual Communitarians dan terakhir budaya Entrepreneurial.

3. Media Education atau pendidikan dalam menggunakan Media menjadi hal yang sangat penting untuk menumbuhkembangkan literasi media, karena jika tidak ada pendidikan media yang cukup baik pendidikan formal hingga informal maka faktor partisipasi dan keaktifan pengguna media akan menjadi yang paling utama dari sesorang dalam penggunaan media mulai dari kebebasan mendapatkan informasi, aturan-aturan yang diciptakan untuk diri sendiri, keingintahuan dan bentuk komunikasi lintas budaya. Bentukbentuk kritis dan kemampuan seseorang hingga kreatifitas menggunakan media akan menjadi keliru dan dapat disalahgunakan, jika pendidikan media tidak diberikan dengan baik sehingga dapat menghantarkan seseorang mendapatkan literasi media yang baik.

\section{DAFTAR REFERENSI}

Carlsson Ulla, et all. (2008). Empowerment Through Media Education: An Intercultural Dialogue. Nordicom. Goteborg University, Sweden.

Castells, Manuel. (2001). The Internet Galaxy: Reflection on the Internet. Business and Society. Oxford University Press, New York.

Fidler, Roger. (1997). Mediamorfosis: Understanding New Media. Pine Forge Press. Thousand Oaks. 
Haryati. (2011). Studi Literasi Informasi Pada Pegawai Negeri Sipil (PNS) Tenaga Pendidik. Jurnal Penelitian Komunikasi. Bandung: BPPKI. Vol. 14, No. 2. hal. 111-126.

Himanen, Pekka. (2001). The Hacker Ethic and the Spirit of the Information Age. New York: Random House.

http://www.apjii.or.id

$\mathrm{http}: / / \mathrm{www}$.isoc.org (the site of the Internet Society)

http://www.kominfo.go.id

International Symposium on Media Education at Grunwald, Federal Republic of Germany (http://www.unesco.org/education/nfsunesco/pdf /MEDIA S.PDF)

Kappas Arvid and Krammer Nicole C. (2011). Face to Face Communication over the Internet. Cambridge University Press, London.
Literasi Internet pada Siswa Sekolah Menengah Pertama oleh Noneng Sumiaty dan Neti Sumiaty. Jurnal Penelitian Komunikasi. Vol. 17. No. 12014 (http://jurnal.kominfo.go.id, diakes terakhir 16 Juli 2015)

Mudjiyanto, Bambang. (2012). Literasi Internet Dan Partisipasi Politik Masyarakat Pemilih dalam Aktivitas Pemanfaatan Media Baru. Jurnal Studi Komunikasi Dan Media. Jakarta: BPPKI. Vol. 16 No. 1. hal. 1-15.

Rahman, A. Harahap. (2010). Literasi Internet Dan Peningkatan Ilmu Pengetahuan. Jurnal Pikom Penelitian komunikasi dan Pembangunan. Medan Balai besar Pengkajian Dan Pengembangan Komunikasi dan Informatika. Vol. 11 No. 3. hal. 403 - 426.

Rogers Everett M. (2003). Diffusion of Innovation, Macmillan Publishing, New York. 